\title{
A Glucose Electrochemical Sensor Based on Glucose Oxidase Immobilized in Aminopropyl-Magnesium Phyllosilicate Nanosheets Matrix
}

\author{
Li-Min Liu*, Fang-Yuan Liu, Xue-Xia Liu, Chun-Fang Huang, Zhi-Jun Wang, De-Yong He \\ School of Chemistry and Chemical Engineering, the Key Laboratory of Coordination Chemistry of \\ Jiangxi Province, Institute of Applied Chemistry, Jinggangshan University, Ji'an, Jiangxi 343009, \\ China \\ *E-mail: $\underline{1 \mathrm{~lm} 24 @ 126 . c o m}$
}

doi: $10.20964 / 2020.07 .06$

Received: 7 February 2020/ Accepted: 4 April 2020 / Published: 10 June 2020

In this work, glucose oxidase (GOD) was immobilized in aminopropyl-magnesium phyllosilicate (AMP) nanosheets matrix to obtain the GOD/AMP composite via an exfoliation-assembly procedure, and a glucose biosensor was constructed by dropping the GOD/AMP composite and nafion film successively onto the glassy carbon electrode surface. The direct electrochemical behavior, the electrocatalytic response to dissolved oxygen and glucose, as well as the ability to detect glucose in real sample were investigated by the methods of cyclic voltammetry and chronoamperometry. The results indicate that the immobilization of GOD in AMP nanosheets matrix maintained the biological activity and facilitated the direct electron transfer of GOD on the glassy carbon electrode surface. The GOD/AMP-composite modified electrode show a sensitively response to glucose, with the linear range of $1.0 \times 10^{-4}$ to $1.1 \times 10^{-3} \mathrm{molL}^{-1}$ and the detection limit of $0.035 \mathrm{mmol} \mathrm{L}{ }^{-1}$. Moreover, the glucose can be detected directly in the real sample of blood serum by this GOD/AMP composite modified electrode.

Keywords: Aminopropyl-magnesium phyllosilicate (AMP), Glucose Oxidase (GOD), Electrochemical biosensor, Direct electrochemistry, Glucose

\section{$\underline{\text { FULL TEXT }}$}

(C) 2020 The Authors. Published by ESG (www.electrochemsci.org). This article is an open access article distributed under the terms and conditions of the Creative Commons Attribution license (http://creativecommons.org/licenses/by/4.0/). 